\title{
Clinical performance and failure modes of pulpless teeth restored with posts: a systematic review
}

\section{Ana Maria Estivalete MARCHIONATTI(a) Vinícius Felipe WANDSCHER ${ }^{(a)}$ Marília Pivetta RIPPE(a) Osvaldo Bazzan KAIZER(a) Luiz Felipe VALANDRO(a)}

(a) Universidade Federal de Santa Maria - UFSM, Faculty of Dentistry, Department of Restorative Dentistry, Santa Maria, RS, Brazil.

Declaration of Interests: The authors certify that they have no commercial or associative interest that represents a conflict of interest in connection with the manuscript.

Corresponding Author: Ana Maria Estivalete Marchionatti E-mail: anamarchionatti@hotmail.com

\begin{abstract}
The aim of this systematic review was to compare the clinical performance and failure modes of teeth restored with intra-radicular retainers. A search was performed on PubMed/Medline, Central and ClinicalTrials databases for randomized clinical trials comparing clinical behavior and failures of at least two types of retainers. From 341 detected papers, 16 were selected for full-text analysis, of which 9 met the eligibility criteria. A manual search added 2 more studies, totalizing 11 studies that were included in this review. Evaluated retainers were fiber (prefabricated and customized) and metal (prefabricated and cast) posts, and follow-up ranged from 6 months to 10 years. Most studies showed good clinical behavior for evaluated intra-radicular retainers. Reported survival rates varied from 71 to $100 \%$ for fiber posts and 50 to $97.1 \%$ for metal posts. Studies found no difference in the survival among different metal posts and most studies found no difference between fiber and metal posts. Two studies also showed that remaining dentine height, number of walls and ferrule increased the longevity of the restored teeth. Failures of fiber posts were mainly due to post loss of retention, while metal post failures were mostly related to root fracture, post fracture and crown and/or post loss of retention. In conclusion, metal and fiber posts present similar clinical behavior at short to medium term follow-up. Remaining dental structure and ferrule increase the survival of restored pulpless teeth. Studies with longer follow-up are needed.
\end{abstract}

Keywords: Tooth, Nonvital; Post and Core Technique; Randomized Controlled Trial; Survival Rate.

\section{Introduction}

Endodontically-treated teeth commonly present great coronal loss due to caries, fractures or access methods for the endodontic treatment. For the reconstruction of endodontically-treated teeth with extensive coronal destruction, intra-radicular posts are recommended to retain the definitive crown restoration ${ }^{1}$ and minimize stress transfer to the tooth, ${ }^{2}$ since non-vital teeth are more prone to fractures than vital teeth. ${ }^{3}$ However, intra-canal anchorage does not strengthen the remaining dental structure. ${ }^{1}$

Selection of the most suitable post system is challenging since complex factors, such as the tooth position on the arch, quantity of remaining dental structure, presence of contact points, and type of restoration to be placed 
must be analyzed. ${ }^{4,5}$ Traditionally, cast posts and cores have been successfully used for restoration of pulpless teeth. However, a disadvantage of their use is that additional amount of dentine is removed during tooth preparation. ${ }^{1,6}$ Also, posts that are more rigid (higher modulus of elasticity) than dentin, such as cast posts and cores, prefabricated zirconium, or prefabricated metal posts may increase the risk of unfavorable failures. Fiber posts are an alternative since they have mechanical properties similar to the dental structure and so generate a more uniform stress distribution to the root, reducing the risk of catastrophic failure., ${ }^{2,7}$

Evidence regarding the most adequate type of post to restore pulpless teeth remains controversial and this issue is still a major concern in dentistry. ${ }^{8}$ Although several observational studies have evaluated the clinical behavior of intra-radicular retainers, they have inherent methodological limitations that restrict direct clinical applicability. Furthermore, most clinical studies are based on retrospective data, without control of the baseline conditions upon which the study was performed. ${ }^{4}$ Randomized clinical trials have the highest level of evidence and produce the best data to guide clinical decisions. ${ }^{9}$

The present systematic review of clinical trials aimed to compare the clinical performance and failure modes of endodontically-treated teeth restored with different intra-radicular retainers. The following research question was investigated: Does the type of intra-radicular retainer affect the clinical performance and failure modes of endodontically-treated teeth?

\section{Methodology}

This systematic review was reported according to the PRISMA Statement guidelines, whenever applicable. ${ }^{10}$

\section{Search strategy}

Medline via PubMed, Cochrane Central Register of Controlled Trials (Central) and ClinicalTrials.gov databases were searched for randomized clinical trials reporting clinical performance and failure modes of intra-radicular posts through July 2016, placing no limit on the publication year. Articles were retrieved in PubMed/MEDLINE using the following search strategy: (((((Nonvital Tooth[MeSH Terms])
OR Devitalized Tooth[MeSH Terms]) OR Pulpless Tooth[MeSH Terms])) OR endodontically treated)) AND $(((()(()(()((($ Post and Core Technique[MeSH Terms])) OR Post Technique[MeSH Terms]) OR Dental Dowel[MeSH Terms]) OR cast dowel) OR metal post) OR metallic post) OR fiber post) OR fiberreinforced post) OR post system)))))) OR prefabricated post)) AND ((((((Clinical Trial[Publication Type]) OR Controlled Clinical Trial[Publication Type]) OR Randomized Controlled Trial[Publication Type]) OR clinical trial)) OR clinical evaluation) OR clinical study). A sensitive search strategy was adapted for CENTRAL. To minimize publication bias, a search including unpublished studies was conducted in ClinicalTrials.gov.

\section{Eligibility criteria}

Inclusion criteria were the following: a) studies should be categorized as randomized clinical trials, and b) at least two intra-radicular retainers should be compared. Studies comparing teeth with or without post placement as well as those comparing different coronal restorations in endodontically-treated teeth were excluded. When more than one publication were found reporting different follow-up periods of the same study, the article with the longest evaluation time was included.

\section{Screening and selection}

First, titles and abstracts were reviewed by two independent examiners. Studies that satisfied the eligibility criteria were selected for full-text reading. Inclusion was based on consensus between the two investigators. Disagreements were discussed with a third reviewer. The references of the selected fulltext articles were also manually reviewed to identify potential studies.

\section{Risk of bias assessment}

Evaluation of the methodological quality of the studies was assessed with the Cochrane Collaboration risk assessment tool for randomized clinical trials. ${ }^{11}$ For each item the articles were classified as having low risk (green circles), high risk (red circles), or unclear risk of bias (yellow circles) if not enough information was given to allow an adequate classification. 


\section{Data extraction}

The following data were extracted from each study: authors and year of publication, types of posts, luting agents, canal insertion mode, remaining dental structure, sample size at randomization and at final evaluation, teeth localization, set-up, mean evaluation time, longest evaluation time, study conclusion, outcomes related to clinical performance (such as survival rate, failure rate, risk of failure and success rate) and failure modes. Data regarding the effect of remaining dentin amount on post survival were also recorded for studies that evaluated this outcome. Annual failure rate (AFR) was calculated for each study as previously described (percentage loss divided by the number of years). ${ }^{12,13}$

\section{Results}

Figure 1 shows a flowchart with the article selection process according to the PRISMA Statement. ${ }^{10}$ The electronic search identified 341 studies, and 275 remained after removing duplicated articles. After evaluating the titles and abstracts, 259 articles did not meet the eligibility criteria and 16 articles were selected for a full text analysis, from which 9 were selected and 7 were excluded ${ }^{14,15,16,17,18,19,20}$. The manual search of the references yielded more 2 articles.

Five studies compared fiber and metal posts, ${ }^{4,21,22,23,24}$ two studies compared metal posts, ${ }^{25,26}$ one study compared prefabricated fiber, custommade fiber and metal posts, ${ }^{27}$ one study compared prefabricated and custom-made fiber posts ${ }^{28}$ one study compared three types of fiber posts ${ }^{29}$ and one study compared two types of fiber posts. ${ }^{30}$ Mean time of follow-up varied from 19.2 months to 109 months. AFR ranged from 0 to $10 \%$. Table summarizes the characteristics of the 10 studies included in the review.

Meta-analysis comparing survival rates was not considered suitable because of the differences of the included studies regarding methods, follow-up time, evaluation criteria and definition of failure.

Considering methodological quality, three studies had a low risk of bias, ${ }^{4,22,23}$ two presented medium risk $^{27,29}$ and six had unclear risk of bias. ${ }^{21,24,25,26,28,30}$ Results of the quality assessment are described in Figure 2.

\section{Fiber posts vs metal posts}

Gbadebo et al. ${ }^{21}$ evaluated the performance of prefabricated glass fiber posts and prefabricated stainless steel posts on endodontically-treated teeth that received metal-ceramic crowns. Six months after posts were placed, the survival rate of glass fiber posts $(n=18)$ was $100 \%$ and of stainless steel posts was $97.5 \%(n=16)$; the groups showed no statistical difference. The only failure recorded was secondary to crown dislodgement in the metal post group.

Sarkis-Onofre et al. ${ }^{22}$ evaluated the survival of endodontically-treated teeth without coronal walls and restored with prefabricated glass fiber posts or cast metal posts and cores and sequential metalceramic crowns. After up to 3 years of follow-up, survival rates were $91.9 \%$ for glass fiber posts $(n=37)$, 97.1\% for cast metal posts and cores $(n=35), 97.5 \%$ for anterior teeth, and $90 \%$ for posterior teeth. There was no statistical difference in the survival rates, considering post type and teeth position in the dental arch. Regarding potential modes of failure, there were two decementations of fiber posts (on an anterior tooth and a premolar) and two non-reparable root fractures (one glass fiber post on a premolar and one cast metal post and core on a molar).

Sterzenbach et al. ${ }^{23}$ compared the survival of prefabricated glass fiber posts and titanium posts cemented on teeth with two or fewer remaining walls. Teeth were restored with metal-ceramic crowns. After 84 months of follow-up, survival rates were 90.2\% for fiber posts and $93.5 \%$ for titanium posts, without statistical difference between groups. For the titanium group $(n=46)$, there were three endodontic failures, while for the glass fiber group $(n=41)$ there was one cervical root fracture on a premolar and one middle root fracture on an incisor (the fractured teeth were extracted), as well as one canine with increased mobility and one core fracture on a premolar.

Schmitter et al. ${ }^{4}$ evaluated the survival of glass fiber posts and screw metal posts. After 5 years, survival of glass fiber posts was $78 \%$ (28 of 39 ) and of metal posts was $50 \%$ ( 21 of 42 ), with a statistical difference between the groups. Concerning failure mode, the 11 failures for glass fiber posts were two post-and-crown debondings, two crown fractures, one apical alteration, and six decayed teeth due to 


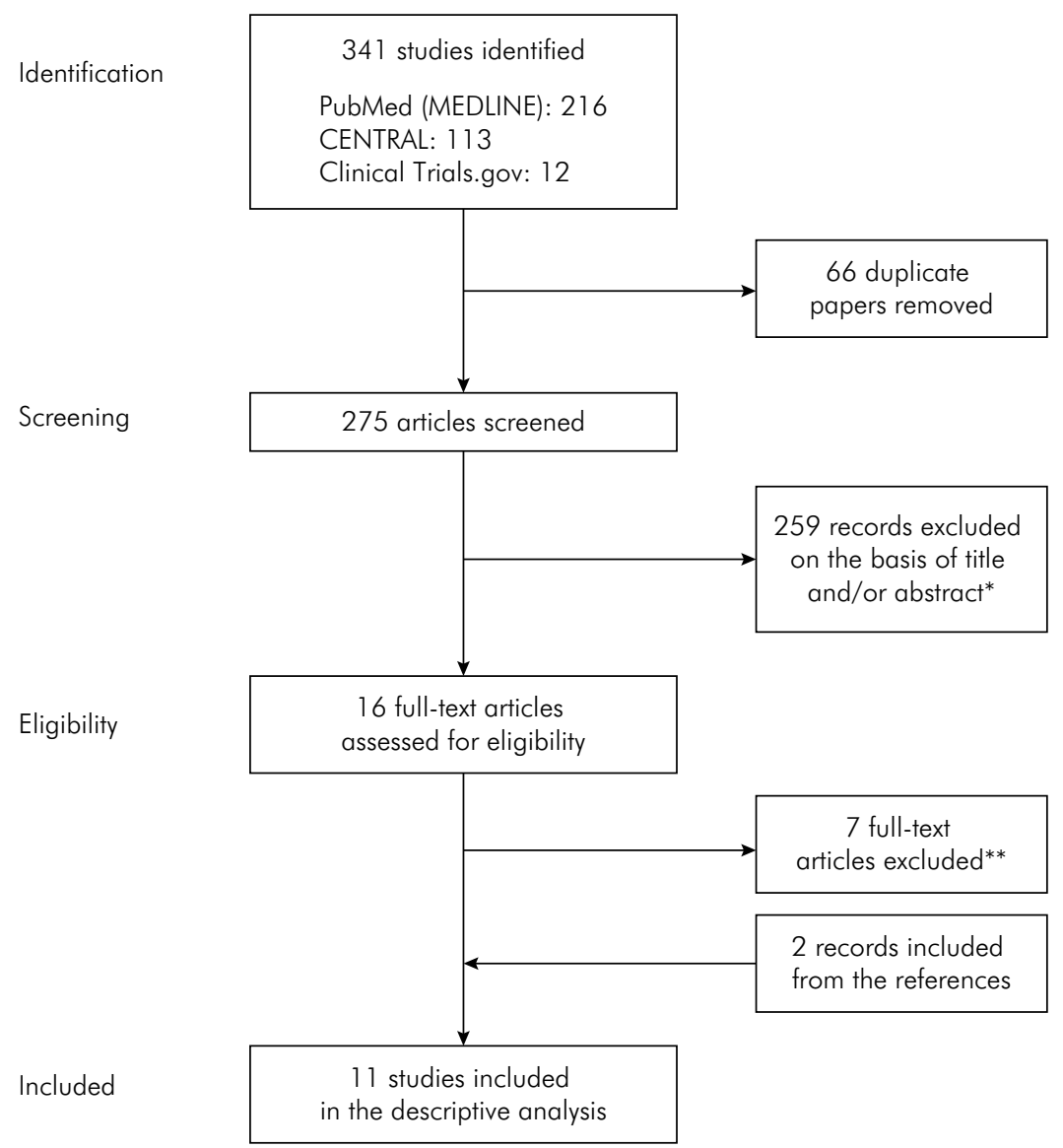

\footnotetext{
*Exclusions: Not randomized clinical trials $(n=211)$; Did not evaluate the outcomes of interest $(n=36)$; No comparison group $(n=12)$.

**Exclusions: Not randomized clinical trials $(\mathrm{n}=4)$ : Mancebo et al., ${ }^{14}$ Ferrari et al., ${ }^{15}$

Salvi et al., ${ }^{16}$ Kwiatkowski and Geller ${ }^{17}$; More recent data available $(n=2)$ : Cagidicaco et al., ${ }^{18}$

Zicari et al. ${ }^{19}$; Unclear if groups were randomized $(n=1)$ : Preethi and Kala. ${ }^{20}$
}

Figure 1. Flow chart depicting the selection of studies for review according to PRISMA statement.

post/core/crown loosening, which the patient did not notice. For the metal posts, the 21 failures were one post debonding, one crown debonding, one loosening of post/crown/core, and 17 teeth that had to be extracted due to fractures or perforations. Anterior teeth showed higher risk of failure than posterior teeth.

King et al. ${ }^{24}$ compared maxillary anterior teeth restored with carbon fiber posts or metal serrated posts and subsequent metal-ceramic crowns. After a mean observation period of 87 months, survival rate for carbon posts $(n=14)$ was $71 \%$ and for metal posts $(n=9) 89 \%$. All carbon post failures were post decementation, while the only failure in the metal post group was due to post fracture.

\section{Prefabricated titanium post vs cast post and core}

Creugers et al. ${ }^{25}$ assessed the influence of post type and remaining dentin height on the survival of endodontically-treated teeth restored with metal cast post-and-core $(n=127)$ and direct metal post with a composite core $(n=150)$. After 5 years, there was no statistical difference in the survival of both post types. For cast posts and cores, there were four root fractures (two incisors, one premolar and one 


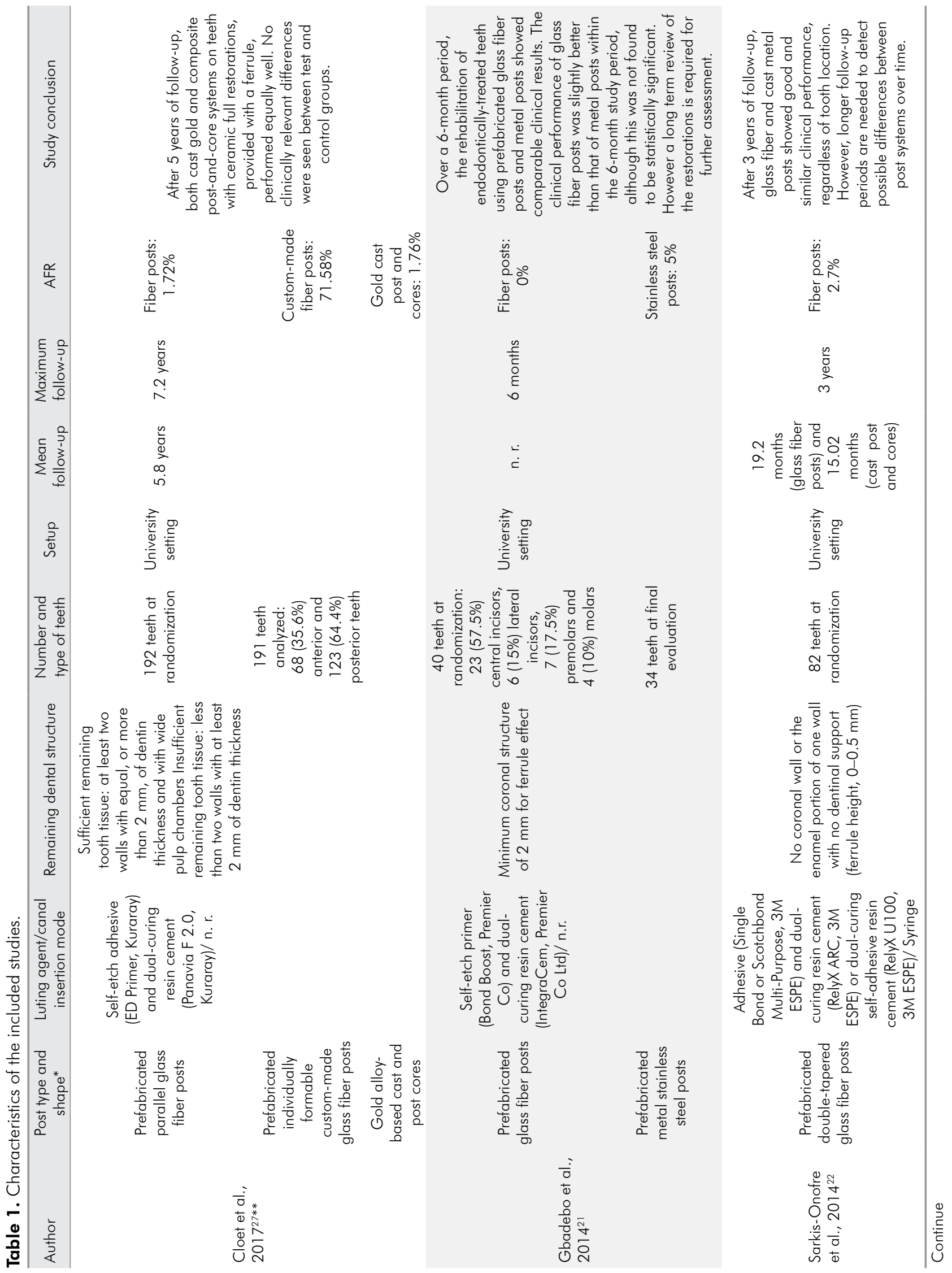




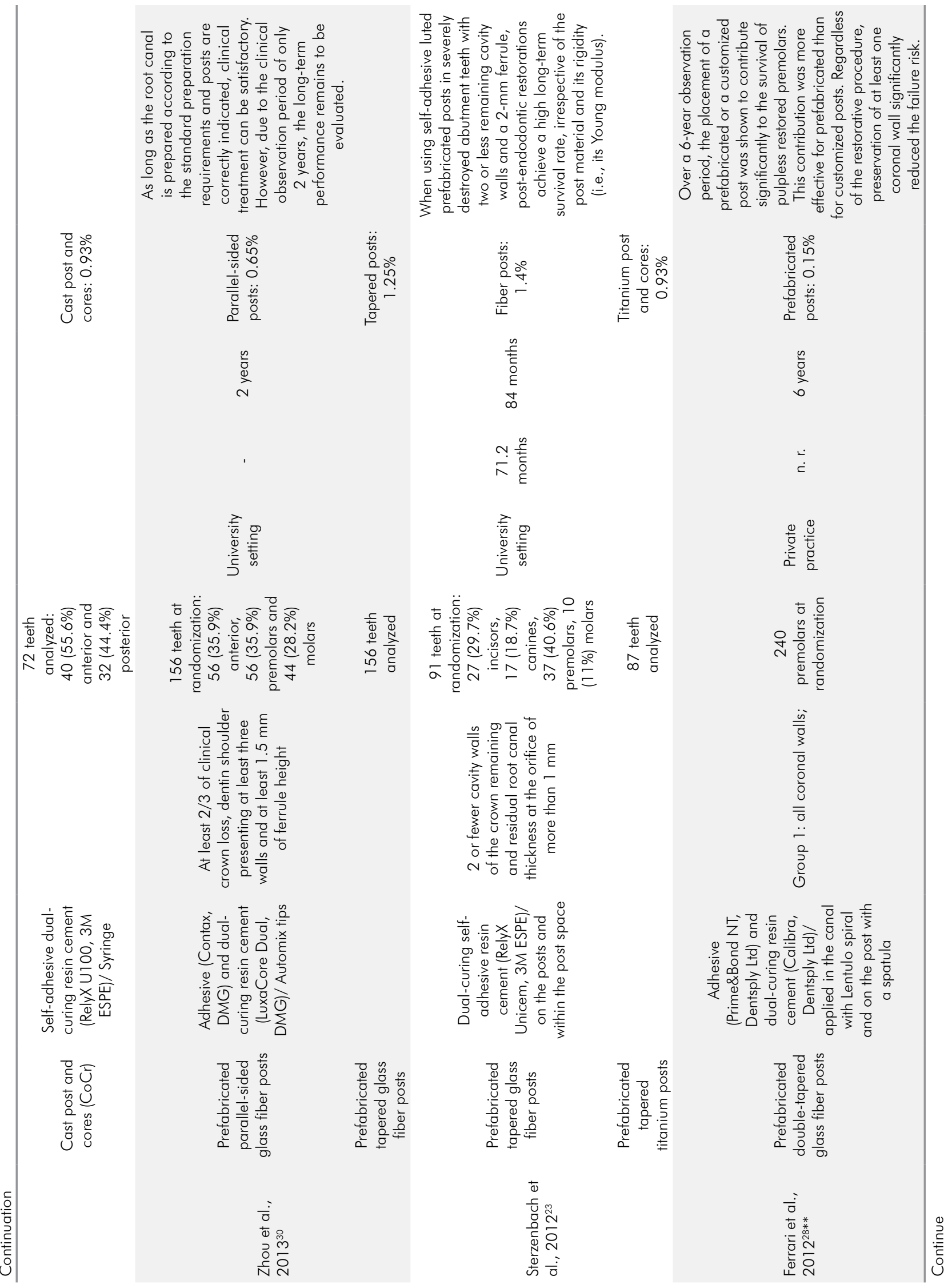




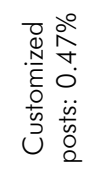

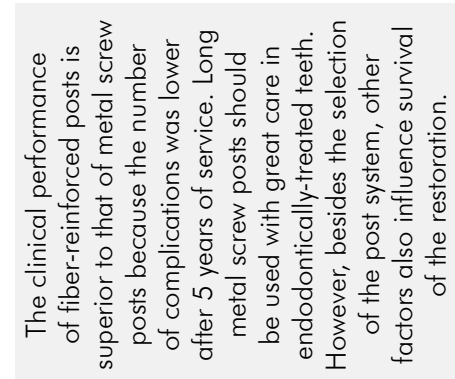

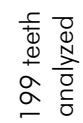

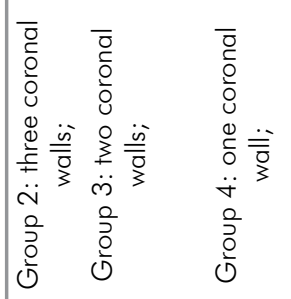
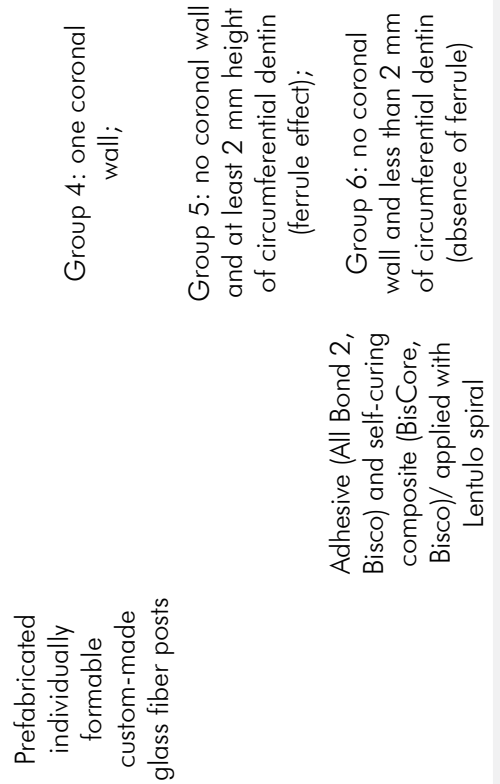

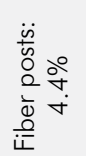

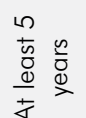

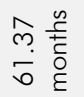

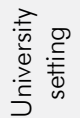
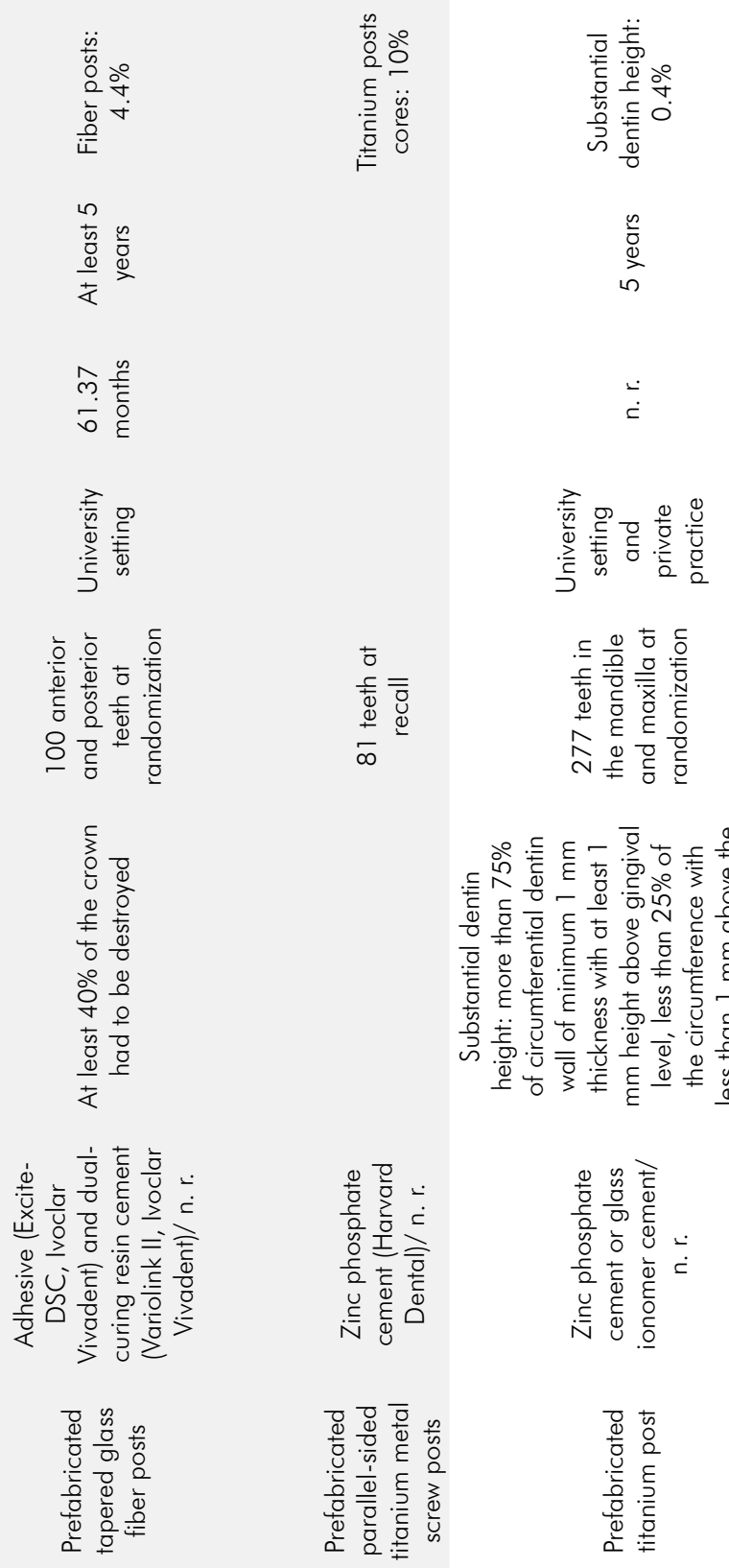

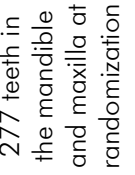
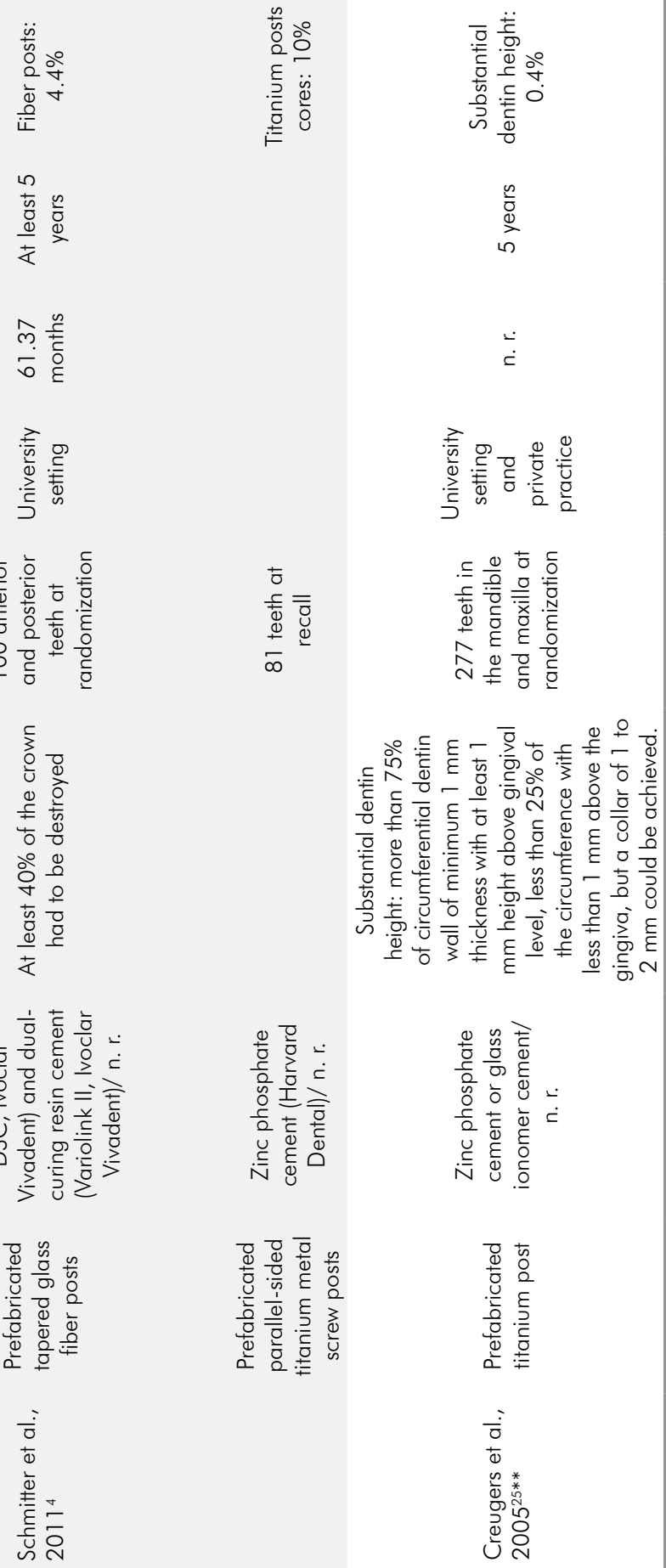

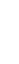

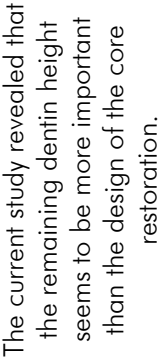

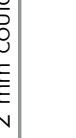




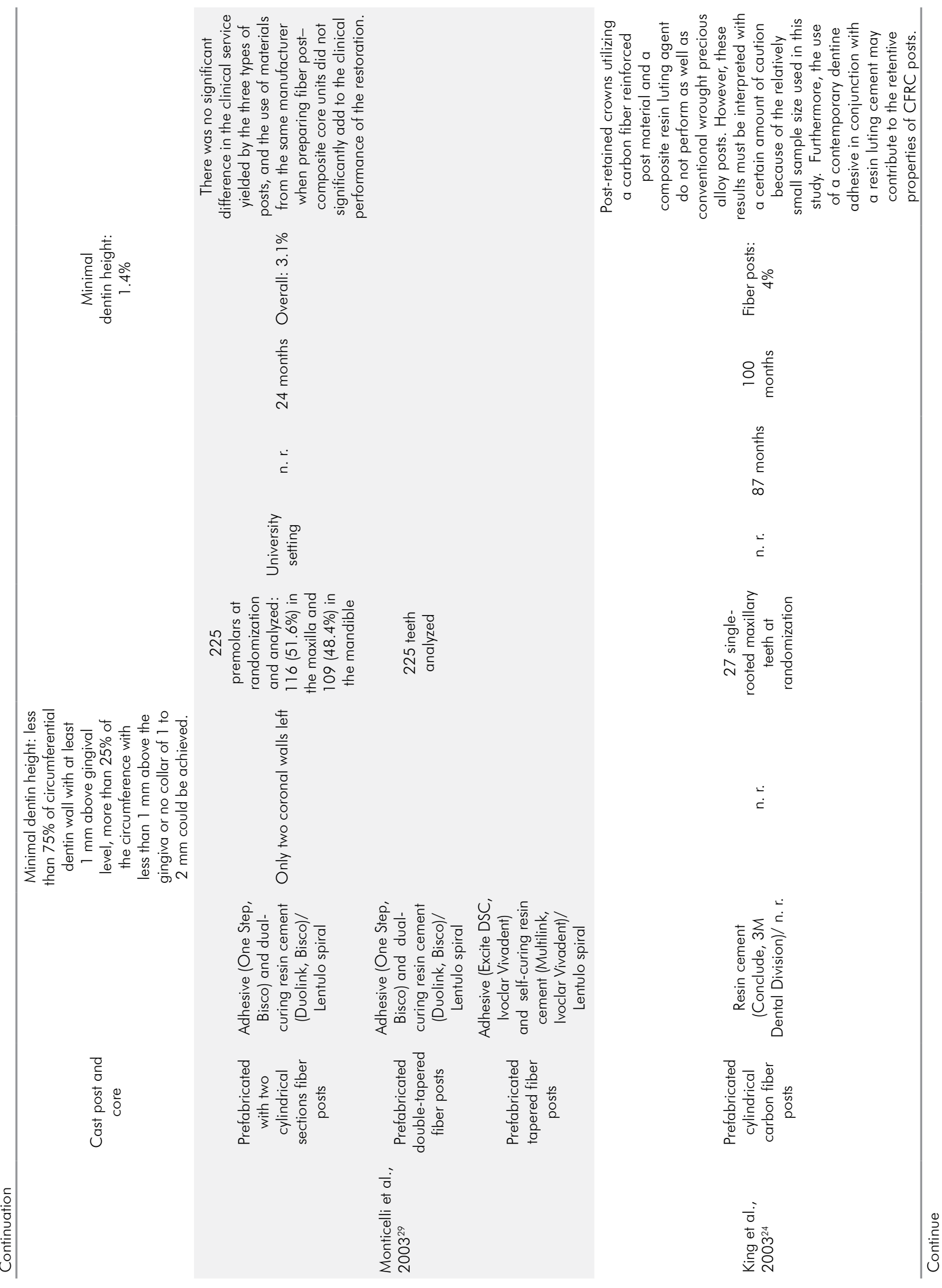




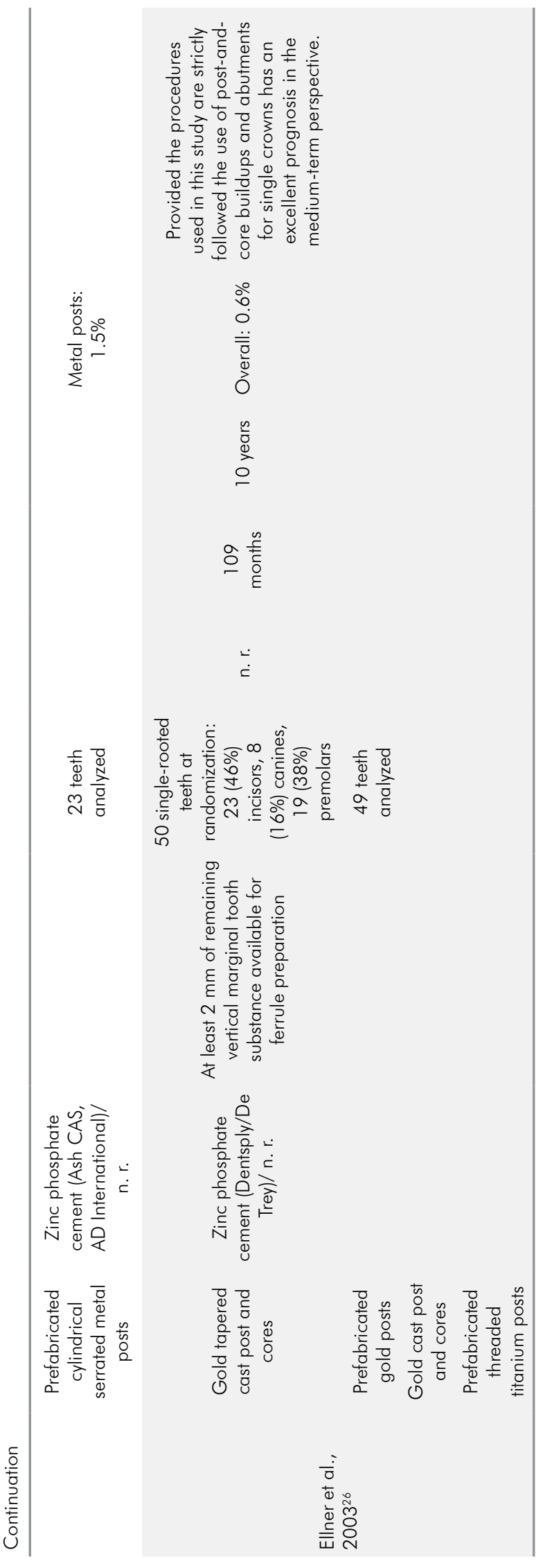

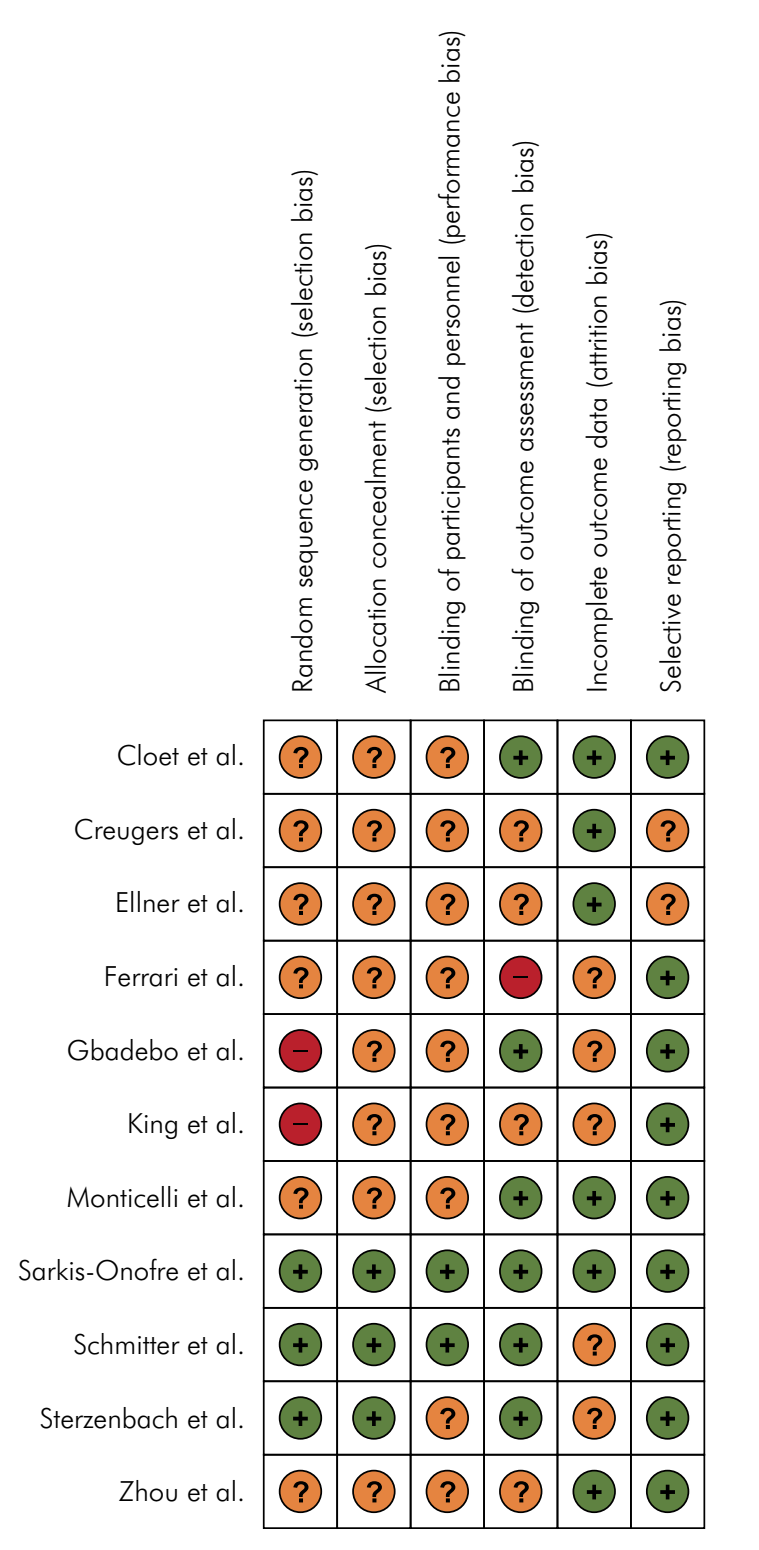

Figure 2. Quality assessment of the selected studies.

molar), two dislodgements (canine and premolar) and one dislodgement with loss of tooth structure (premolar), while for direct posts there were three dislodgments with loss of tooth material (one incisor and two premolars), two root fractures (incisor and premolar) and one tooth loss (molar). From these outcomes, five root fractures distributed in both groups and also in a third group without post placement (which was not included in the present review) were considered early failures, independent from clinical aging, and excluded from the survival assessments. It was not specified if root fractures were repairable 
or not. Survival in teeth with substantial dentin height $(98 \%)$ was statistically superior to teeth with minimal dentin height (93\%).

\section{Gold cast posts and cores vs prefabricated gold posts vs prefabricated titanium posts}

Ellner et al. ${ }^{26}$ evaluated clinical performances of four post-and-core combinations: Group 1conventional tapered gold cast posts and cores $(n=14)$, Group 2 - gold prefabricated posts with gold cast cores $(n=13)$, Group 3 - gold cast posts and cores after prefabricated burnout posts $(\mathrm{n}=13)$, and Group 4 threaded titanium posts with cores in chemicallycured composite resin $(n=10)$. Posts were placed on single-rooted teeth with $2 \mathrm{~mm}$ of ferrule effect and restored with single metal-ceramic or gold-acrylic crowns. After up to 10 years of follow-up, there was no statistical difference in mean functional times between the groups. Overall failure rate was $6 \%$. Regarding technical failures, Group 3 showed one root fracture on a canine (the authors did not mention if it was reparable), and Group 4 showed two failures on an incisor and a premolar due to loss of retention.

\section{Prefabricated fiber posts vs custom-made fiber posts vs gold cast posts and cores}

Cloet et al. ${ }^{27}$ compared the clinical outcomes of prefabricated glass fiber posts, custom-made glass fiber posts and gold cast posts and cores (control). After 5 years of follow-up, there were 22 irreparable failures: six (one in anterior and five in posterior teeth) in the prefabricated fiber posts (n = 65), two (anterior teeth) in the custom-made fiber post group $(n=26)$ and 14 (six in anterior and eight in posterior teeth) in the cast post and core group $(n=101)$. The failures were due to root fracture, post fracture into the root canal, caries, and endodontic and periodontal failure. There were 20 reparable failures: seven (three in anterior and four in posterior teeth) in the prefabricated fiber post group, three (anterior teeth) in the custom-made fiber post group, and 10 (six in anterior and four in posterior teeth) in the cast post and core group; reasons were loss of retention of the post, endodontic failure, and post fracture. Success probabilities were $81.6 \%$ for fiber posts, $87.8 \%$ for custom-made posts and $86.9 \%$
(CI: 80.0-93.8) for the control, while the survival probabilities were $91.4 \%$ for fiber posts, $92.1 \%$ for custom-made posts and $91.2 \%$ for the control group, without statistical differences.

\section{Prefabricated fiber posts vs custom-made fiber posts}

Ferrari et al. ${ }^{28}$ evaluated the amount of coronal dentin and type of post (prefabricated double-tapered or customized fiber post, i.e., glass fibers were adapted in the canal space) on the survival of premolars restored with metal-ceramic crowns. After 6 years of follow-up, teeth restored with prefabricated posts had higher success $(76.6 \%)$ and survival rates (99.1\%) than teeth restored with customized posts $(61.3 \%$ and $97.2 \%$, respectively). Teeth with the ferrule effect showed significantly less risk of failure than teeth without it. Also, success rate decreased from $100 \%$ when a tooth had four remaining walls, to $69.8 \%$ when there were two remaining walls, and 52.9\% when only one wall remained. Prefabricated fiber posts had fewer failures than custom-made posts; for both cases, failures related to the restoration assembly were mainly post/core fracture, crown dislodgment, or post debonding.

\section{Cylindrical fiber posts vs tapered fiber posts vs double-tapered fiber posts}

Monticelli et al..$^{29}$ compared the clinical performance of premolars restored with tapered $(n=75)$, double-tapered $(\mathrm{n}=75)$ and two-cylindrical section $(\mathrm{n}=75)$ fiber posts and all-porcelain crowns. After 24 months of follow-up, the $6.2 \%$ failure rate was homogeneously distributed among the groups: there were eight post debondings and six endodontic failures.

\section{Cylindrical fiber posts vs tapered fiber posts}

Zhou et al. ${ }^{30}$ evaluated the clinical performance of cylindrical and tapered fiber posts. After 2 years of follow-up, there was no statistical difference between the survival rate of the cylindrical and tapered posts (98.7\% and $97.5 \%$, respectively). Failures consisted of one post fracture (canine) in the cylindrical post group ( $\mathrm{n}=77)$, and one post fracture (incisor) and a post debonding (incisor) in the tapered post group $(n=79)$. 


\section{Discussion}

The restoration of endodontically-treated teeth is usually difficult, and intra-radicular posts are often needed to retain the coronal restoration when there is substantial tissue loss. This systematic literature review comprised randomized clinical trials that compared intra-radicular retainers based on the clinical performance and failures of endodontically-treated teeth.

Most studies that evaluated metal and fiber posts $^{21,22,23,27}$ found similar survival rates for both types of retainers, except for Schmitter et al. ${ }^{4}$ that found higher survival for glass fiber posts and King et al., ${ }^{24}$ that found higher survival for metal posts. Interestingly, these studies show a longer follow-up period than Gbadebo et al.,r ${ }^{21}$ Sarkis-Onofre et al., ${ }^{22}$ Sterzenbach et al., ${ }^{23}$ and Cloet et al. ${ }^{27}$ It is probable that a longer evaluation period would be needed to detect possible differences in the latter studies. In the study by Cloet et al., ${ }^{27}$ prefabricated glass fiber posts and custom-made glass fiber posts were cemented on teeth with insufficient remaining dental structure with small and wide root canals, respectively, while gold cast posts and cores were cemented on teeth with either sufficient or insufficient dentine. Therefore, it is possible that a higher number of failures could have been observed if cast posts and cores had also been cemented only on teeth with insufficient remaining structure, since amount of tooth structure affects the longevity of restored pulpless teeth. ${ }^{25}$

The studies that compared metal posts did not find statistical differences between prefabricated titanium posts and cast posts and cores after 5 years ${ }^{25}$ and neither among gold cast posts and cores, prefabricated gold posts, and prefabricated titanium posts after up to 10 years. ${ }^{26}$ These results may be related to the fact that metal posts, although being made of different materials, present similar mechanical properties and, consequently, behave in a comparable way regarding stress distribution on the root at the restoration assembly. ${ }^{31}$

In the study by Monticelli et al., ${ }^{29}$ and by Zhou et al., ${ }^{30}$ the failures that occurred were similarly distributed among the groups, which may be associated with the use of fiber posts (with almost the same elastic modulus) in all groups. However, since the studies present a short-term follow-up time of 2 years, it is possible that after a longer period, differences due to diverse post shapes may be detected. It is known that cylindrical posts result in good retention, but they require more aggressive dentine removal during canal preparation; on the other hand, although conical posts are less retentive than cylindrical posts, tooth preparation is more conservative and removes less dental structure. ${ }^{32}$ Double-tapered posts are conical along the apical portion and have a large coronal diameter to obtain better adaptation and retention to the root canal, which results in little removal of apical tooth structure and adequate cervical adaption. ${ }^{33}$ Finite element analysis studies show that cylindrical posts generate less stress on the dentin than conical posts and that the latter concentrate stress on the apical region of the root. The reduction in shear stress for cylindrical posts in comparison with conical posts could lead to long-term lower rates of debonding for parallel-sided posts. ${ }^{34,35}$

Clinically, in addition to the survival of the restoration, the mode of failure is also a crucial aspect to be evaluated since it determines if the tooth may be repaired and continue in function. ${ }^{36}$ Post and post/crown/core loss of retention were the most common failures for fiber posts, especially in the anterior region. Wandscher et al. ${ }^{37}$ showed that shear stress is strongly present in the central region of endodontically treated anterior teeth restored with fiber posts during load application, inducing adhesive failures in the post/cement/dentine interfaces. For most studies, metal posts presented diverse types of failure, including crown and/or post loss of retention, endodontic failures and post fractures, except for Schmitter et al., that observed 17 failures due to root fracture or perforation. However, the high level of catastrophic failures in addition to the high AFR of $10 \%$ in such study may be attributed to the fact that the posts had active retention and were threaded to the canal, possibly generating high stress concentration on the root. ${ }^{38}$ Of the articles that reported the position of the failed teeth, Sarkis-Onofre et al..$^{22}$ reported a higher number of failures for posterior teeth and Cloet et al. ${ }^{27}$ found equally distributed failures on 
anterior and posterior teeth. Sterzenbach et al. ${ }^{23}$ found more failures in the anterior region, while Schmitter ${ }^{4}$ showed a higher risk of failure for anterior teeth. Some studies indicated that anterior teeth presented more failures than posterior teeth due to the action of horizontal forces that promote bending of the post; as a consequence, tensile, compressive and shear stresses act harmfully on the restored structure ${ }^{37}$ differently from vertical compressive forces developed on molars and premolars. ${ }^{5,39}$

Fiber post loss of retention was commonly found in the included studies. A recent systematic review showed that the method of resin cement application and post pretreatment are factors that may affect the retention of glass fiber posts. ${ }^{40}$ Applying the cement into the root canal (e.g. with lentulo spirals or syringes) increases post retention in relation to applying the luting agent also around the post. Unfortunately, no information regarding the method of cement application was found for most studies: only 3 studies reported cement insertion inside the root canal, ${ }^{22,29,30}$ while 2 articles reported cement application on the post and into the root canal. ${ }^{23,28}$ In addition, only Sarkis-Onofre et al. ${ }^{22}$ and Sterzenbach et al. ${ }^{23}$ reported performing fiber post pretreatment (cleaning with ethanol/silane application and cleaning with acetone, respectively). Cleaning fiber posts improves bond strength in comparison with silanization without cleaning when regular resin cements are used. ${ }^{40}$ The mode of cement application and post pretreatment should be described in detail in future research since they may affect post adhesion on the root dentin.

The current study focused on the clinical behavior of different posts; for this reason, studies comparing post-restored teeth with non-restored teeth or teeth restored without posts were not included. In cases of limited tissue loss, post placement does not seem to affect the survival of endodontically-treated teeth. ${ }^{41}$ However, when a post is placed, the remaining dental structure influences the performance of root-filled teeth. Ferrari et al. ${ }^{28}$ and Creugers et al. ${ }^{25}$ showed that presence of ferrule and preservation of coronal walls increased survival rates of post-restored teeth. Such findings confirm the importance of preserving tooth structure on the performance of endodontically-treated teeth ${ }^{41}$ which may be even more important than the choice of the core. ${ }^{25}$

The results of the present systematic review may be limited by the risk of bias of the included studies. The quality assessment showed that most studies had unclear risk of bias, which means that important methodological parameters for quality assessment need to be better described in future studies. Only three studies presented low risk and two studies had medium risk of bias. Blinding of participants, random sequence generation and allocation concealment were the most poorly reported or omitted parameters. Considering that studies with a low risk of bias are more reliable, future clinical studies should be more careful about methodological parameters to reduce bias risk, as well as about properly reporting study design and execution. Another limitation of this review is the restricted follow-up period of most included studies. Well-designed randomized clinical trials with longer follow-up time are needed to provide more accurate information on the clinical performance and failure modes of teeth restored with different intra-radicular retainers.

\section{Conclusion}

Based on the short- to medium-term randomized clinical trials reviewed, it was concluded that metal and fiber posts present similar clinical performance and represent good alternatives to restore endodontically-treated teeth, but studies with a longer evaluation time are needed to obtain long-term evidence about the performance of intraradicular post systems. Types of failure observed when metal posts are used include post fracture, root fracture, and crown and/or post loss of retention, while when fiber posts are used, post and post/crown/core loss of retention are the most common reasons for failure. The ferrule effect and the amount of residual dental structure influence the survival of endodontically-treated teeth for both metal and fiber posts, as failure rates increase because of reduced tooth structure. 


\section{References}

1. Kimmel SS. Restoration of endodontically treated tooth containing wide or flared canal. N Y State Dent J. 2000;66(10):36-40.

2. Coelho CS, Biffi JC, Silva GR, Abrahão A, Campos RE, Soares CJ. Finite element analysis of weakened roots restored with composite resin and posts. Dent Mater J. 2009;28(6):671-8. https://doi.org/10.4012/dmj.28.671

3. Tang W, Wu Y, Smales RJ. Identifying and reducing risks for potential fractures in endodontically treated teeth. J Endod. 2010;36(4):609-17. https://doi.org/10.1016/i.joen.2009.12.002

4. Schmitter M, Hamadi K, Rammelsberg P. Survival of two post systems: five-year results of a randomized clinical trial. Quintessence Int. 2011;42(10):843-50.

5. Naumann M, Blankenstein F, Kiessling S, Dietrich T. Risk factors for failure of glass fiber-reinforced composite post restorations: a prospective observational clinical study. Eur J Oral Sci. 2005;113(6):519-24. https://doi.org/10.1111/i.1600-0722.2005.00257.x

6. Soares CJ, Valdivia AD, Silva GR, Santana FR, Menezes MS. Longitudinal clinical evaluation of post systems: a literature review. Braz Dent J. 2012;23(2):135-740. https://doi.org/10.1590/S0103-64402012000200008

7. Maroulakos G, Nagy WW, Kontogiorgos ED. Fracture resistance of compromised endodontically treated teeth restored with bonded post and cores: an in vitro study. J Prosthet Dent. 2015;114(3):390-7. https://doi.org/10.1016/i.prosdent.2015.03.017

8. Bolla M, Muller-Bolla M, Borg C, Lupi-Pegurier L, Laplanche O, Leforestier E. Root canal posts for the restoration of root filled teeth. Cochrane Database Syst Rev. 2007;24;(1):CD004623. https://doi.org/10.1002/14651858.CD004623.pub2

9. Fokkinga WA, Kreulen CM, Bronkhorst EM, Creugers NH. Up to 17-year controlled clinical study on post-and-cores and covering crowns. J Dent. 2007;35(10):778-86. https://doi.org/10.1016/i.jdent.2007.07.006

10. Moher D, Liberati A, Tetzlaff J, Altman DG. Preferred reporting items for systematic reviews and meta-analyses: the PRISMA statement. Int J Surg. 2010;8(5):336-41. https://doi.org/10.1016/i.ijsu.2010.02.007

11. Higgins JPT, Green S, editors. Cochrane handbook for systematic reviews of interventions Version 5.1.0. London: The Cochrane Collaboration; 2011.

12. Peumans M, De Munck J, Mine A, Van Meerbeek B. Clinical effectiveness of contemporary adhesives for the restoration of non-carious cervical lesions: a systematic review. Dent Mater. 2014;30(10):1089-103. https://doi.org/10.1016/i.dental.2014.07.007

13. Manhart J1, Chen H, Hamm G, Hickel R. Buonocore Memorial Lecture. Review of the clinical survival of direct and indirect restorations in posterior teeth of the permanent dentition. Oper Dent. 2004;29(5):481-508.
14. Mancebo JC, Jiménez-Castellanos E, Cañadas D. Effect of tooth type and ferrule on the survival of pulpless teeth restored with fiber posts: a 3-year clinical study. Am J Dent. 2010;23(6):351-6.

15. Ferrari M, Cagidiaco MC, Grandini S, De Sanctis M, Goracci C. Post placement affects survival of endodontically treated premolars. J Dent Res. 2007;86(8):729-34. https://doi.org/10.1177/154405910708600808

16. Salvi GE, Siegrist Guldener BE, Amstad T, Joss A, Lang NP. Clinical evaluation of root filled teeth restored with or without post-and-core systems in a specialist practice setting. Int Endod J. 2007;40(3):209-15. https://doi.org/10.1111/j.1365-2591.2007.01218.x

17. Kwiatkowski S, Geller W. A preliminary consideration of the glass-ceramic dowel post and core. Int J Prosthodont. 1989;2(1):51-5.

18. Cagidiaco MC, García-Godoy F, Vichi A, Grandini S, Goracci C, Ferrari M. Placement of fiber prefabricated or custom made posts affects the 3 -year survival of endodontically treated premolars. Am J Dent. 2008;21(3):179-84.

19. Zicari F, Van Meerbeek B, Debels E, Lesaffre E, Naert I. An up to 3-year controlled clinical trial comparing the outcome of glass fiber posts and composite cores with gold alloy-based posts and cores for the restoration of endodontically treated teeth. Int J Prosthodont. 2011;24(4):363-72.

20. Preethi G, Kala M. Clinical evaluation of carbon fiber reinforced carbon endodontic post, glass fiber reinforced post with cast post and core: a one year comparative clinical study. J Conserv Dent. 2008;11(4):162-7. https://doi.org/10.4103/0972-0707.48841

21. Gbadebo OS, Ajayi DM, Oyekunle OO, Shaba PO. Randomized clinical study comparing metallic and glass fiber post in restoration of endodontically treated teeth. Indian J Dent Res. 2014;25(1):58-63. https://doi.org/10.4103/0970-9290.131126

22. Sarkis-Onofre R, Jacinto RC, Boscato N, Cenci MS, Pereira-Cenci T. Cast metal vs. glass fibre posts: a randomized controlled trial with up to 3 years of follow up. J Dent. 2014;42(5):582-7. https://doi.org/10.1016/i.jdent.2014.02.003

23. Sterzenbach G, Franke A, Naumann M. Rigid versus flexible dentine-like endodontic posts: clinical testing of a biomechanical concept: seven-year results of a randomized controlled clinical pilot trial on endodontically treated abutment teeth with severe hard tissue loss. J Endod. 2012;38(12):1557-63. https://doi.org/10.1016/i.joen.2012.08.015

24. King PA, Setchell DJ, Rees JS. Clinical evaluation of a carbon fibre reinforced carbon endodontic post. J Oral Rehabil. 2003;30(8):785-9. https://doi.org/10.1046/j.1365-2842.2003.01178.x 
25. Creugers NH, Mentink AG, Fokkinga WA, Kreulen CM. 5 -year follow-up of a prospective clinical study on various types of core restorations. Int J Prosthodont. 2005;18(1):34-9. https://doi.org/10.1016/i.prosdent.2005.05.013

26. Ellner S, Bergendal T, Bergman B. Four post-and-core combinations as abutments for fixed single crowns: a prospective up to 10-year study. Int J Prosthodont. 2003;16(3):249-54.

27. Cloet $E$, Debels $E$, Naert I. Controlled clinical trial on the outcome of glass fiber composite cores versus wrought posts and cast cores for the restoration of endodontically treated teeth: a 5-year follow-up study. Int J Prosthodont. 2017;30(1):71-9. https://doi.org/10.11607/iip.4861

28. Ferrari M, Vichi A, Fadda GM, Cagidiaco MC, Tay FR, Breschi $L$ et al. A randomized controlled trial of endodontically treated and restored premolars. J Dent Res. 2012;91(7 Suppl):72-8S. https://doi.org/10.1177/0022034512447949

29. Monticelli F, Grandini S, Goracci C, Ferrari M. Clinical behavior of translucent-fiber posts: a 2-year prospective study. Int J Prosthodont. 2003;16(6):593-6.

30. Zhou XW, Liu XY, Zhao J. A 2-year follow-up of endodontically treated teeth restored with either tapered or parallel-sided glass-fiber posts. Chin J Tissue Eng Res. 2013;17(12):2164-71.

31. Adanir N, Belli S. Stress analysis of a maxillary central incisor restored with different posts. Eur J Dent. 2007;1(2):67-71.

32. Cheung W. A review of the management of endodontically treated teeth. Post, core and the final restoration. J Am Dent Assoc. 2005;136(5):611-9. https://doi.org/10.14219/jada.archive.2005.0232

33. Broch J, Marchionatti AM, Bergoli CD, Valandro LF, Kaizer $\mathrm{OB}$. Fracture resistance of weakened roots restored with different intracanal retainers. Gen Dent. 2015;63(3):58-63.
34. Asmussen E, Peutzfeldt A, Sahafi A. Finite element analysis of stresses in endodontically treated, dowel-restored teeth. J Prosthet Dent. 2005;94(4):321-9. https://doi.org/10.1016/i.prosdent.2005.07.003

35. Pegoretti A, Fambri L, Zappini G, Bianchetti M. Finite element analysis of a glass fibre reinforced composite endodontic post. Biomaterials. 2002;23(13):2667-82. https://doi.org/10.1016/S0142-9612(01)00407-0

36. Figueiredo FE, Martins-Filho PR, Faria-E-Silva AL. Do metal post-retained restorations result in more root fractures than fiber post-retained restorations? A systematic review and meta-analysis. J Endod. 2015;41(3):309-16. https://doi.org/10.1016/i.joen.2014.10.006

37. Wandscher VF, Bergoli CD, Limberger IF, Ardenghi TM, Valandro LF. Preliminary results of the survival and fracture load of roots restored with intracanal posts: weakened vs nonweakened roots. Oper Dent. 39(5):541-55. https://doi.org/10.2341/12-465

38. Santos Filho PC, Soares PV, Reis BR, Veríssimo C, Soares CJ. Effects of threaded post placement on strain and stress distribution of endodontically treated teeth. Braz Oral Res. 2013;27(4):305-10. https://doi.org/10.1590/S1806-83242013000400003

39. Schmitter M, Rammelsberg P, Gabbert O, Ohlmann B. Influence of clinical baseline findings on the survival of 2 post systems: a randomized clinical trial. Int J Prosthodont. 2007;20(2):173-8.

40. Skupien JA, Sarkis-Onofre R, Cenci MS, Moraes RR, Pereira-Cenci T. A systematic review of factors associated with the retention of glass fiber posts. Braz Oral Res. 2015;29(1):1-8. https://doi.org/10.1590/1807-3107BOR-2015.vol29.0074

41. Aurélio IL, Fraga S, Rippe MP, Valandro LF. Are posts necessary for the restoration of root filled teeth with limited tissue loss? A structured review of laboratory and clinical studies. Int Endod J. 2016;49(9):827-35. https://doi.org/10.1111/iej.12538 